\title{
New trends in determining the authenticity of corn oil
}

\author{
By M. Hassan El-Mallah (1), T. Murui (2) and S. El-Shami (1) \\ (1) National Research Centre, Fats and Oils Res. Lab. Dokki, Cairo, Egypt.
}

(2) Salad Co., Tokyo, Japan.

The paper has been presented in the $14^{\text {th }}$ SAAFOST International Congress and Exhibition, Pretoria, 14 Sept. 1997, South Africa.

\section{RESUMEN}

Nuevas tendencias en la determinación de la autenticación de aceite de maíz.

Para establecer la autenticación del aceite se ha utilizado la cromatografía líquida de alta eficacia de triacilgliceroles y componentes menores tales como los esteroles y esterilglicosidos libres y acilados, tocoferoles y alcoholes isoprenicos. También se ha llevado a cabo el análisis por cromatografía gas-líquido de los esteroles totales asi como de sus derivados silanizados.

Se analizaron aceites genuinos de colza, girasol y maíz así como mezclas de aceites de maíz con los otros dos aceites.

Se determinaron directamente los triacilgliceroles y tocoferoles en los aceites mientras que los cuatro lipidos esterólicos (esteroles y esterilglicósidos libres y acilados) y alcoholes isoprenicos se aislaron y se transformaron en sus antroil nitril derivados.

Se concluyó que el análisis de los componentes menores en combinación con el de los triacilgliceroles es más ventajoso para la autenticación del aceite de maíz. Sin embargo a este respecto son más decisivos los alcoholes isoprenicos.

La variabilidad natural de los componentes en los aceites de diferentes orígenes puede modificar los límites de decisión.

PALABRAS-CLAVE: Aceite de maíz - Autenticación - Componentes menores - Triacilgliceroles.

\section{SUMMARY}

New trends in determining the authenticity of corn oil.

HPLC analysis of triacylglycerols and minor components, such as free and acylated sterols, and sterylglycosides, tocopherols and isoprenoid alcohols, have been employed for establishing oil authenticity. GLC analysis of the whole sterols as their TMS derivatives has been also conducted.

Genuine oils, namely, rapeseed, sunflower and corn oil as well as corn oil admixtures with the two oils were analyzed.

Triacylglycerols and tocopherols were directly determined in the oils whereas the four sterol in lipids (free and acylated sterols and sterylglycosides) and isoprenoid alcohols were isolated and derivatized into their anthroyl nitrile derivatives.

It was concluded that the analysis of minor components in combination with triacylglycerols is more advantageous for authentication of corn oil. However, isoprenoid alcohols are more decisive in this respect.

Natural variability of the components in the oils from different origins can modify the detection limits.

KEY-WORDS: Authentication - Corn oil - Minor components - Triacylglycerols.

\section{INTRODUCTION}

Checking the purity of oils is necessary since there is a possibility that they are illegally mixed with cheaper oils. Therefore, authenticity of oils is of great importance from the stand points of both commercial value and health aspects, accordingly, efficient analytical methods are required for authentication of oils and to ensure the compliance with legislations.

Various conventional methods, namely, chromatographic $(1,2,3)$, spectrophotometric analysis (4), as well as specific reactions (5) were employed to determine oil authenticity.

For establishing whether the oils are pure or adulterated with other oils, ranges of tocopherols, sterols, triglyceride and 2-position fatty acids has been obtained on oils of major commercial interest (6). An overview of the current status and recent trends in improving methodologies for detecting the adulteration of olive oil has been presented (7). Also updated methods for the detection of adulterants and contaminants in edible oils and fats, in the form of a critical review, have been reported (8). These methods have been briefly described along with sensitivities and limitations.

New technique of stable carbon isotope ratio analysis, using gas chromatography combustionisotope ratio-mass spectrophotometry, has been developed in establishing maize oil purity $(9,10)$. The proof of maize oil purity is more difficult by the conventional methods of analysis.

In the last few years, high performance liquid chromatography (HPLC) has been employed for the analysis of oil triacylglycerols $(11,12,13)$ and has been efficiently used in establishing the oil purity $(14,15,16,17)$.

The analysis of minor components of oils, has also received the interest of some authors for the authentication of edible oils $(18,19)$. Thus, the recognition of adulteration by other oils via direct analysis of some minor components, was shown only for olive oil (18). On the other side, isoprenoid alcohol compositions of oils were determined and 
the method was applied on the detection of cottonseed in other oils (19). Development of steryl ester analysis for the detection of admixtures of vegetable oils using HPLC-GLC has been recently reported (20).

The main objective of this study is to apply high efficient HPLC methods for analysis of minor components, namely free and acylated forms of both sterols and sterylglycosides, tocopherols and isoprenoid alcohols in combination with triacylglycerol components. By analyzing these minor components with triacylglycerols, highly specific information about the identity of corn oil can be provided.

Rapeseed, sunflower and corn oils are selected as pure oils whereas mixtures of corn oil, with low levels of the other two oils, llave been constructed as model admixtures. The HPLC methods of analysis require the isolation of the free and acylated forms of sterols and steryl glycosides as well as the isoprenoid alcohols. These components are then derivatized into their 9- and 1 -anthroylnitriles that can be detected in very minute quantities.

Tocopherols and triacylglycerols are directly determined by HPLC whereas as the whole sterols have been isolated from the unsaponifiable matter and determined by capillary GLC as their TMS.

The results can throw light on the possibility of achieving new parameters via the analysis of these minor components, particularly some of the minor components have not been hitherto reported for the detection of corn oil adulteration.

\section{EXPERIMENTAL}

\subsection{Triacylglycerols $(12,6)$}

A sample of $10 \mu \mathrm{l}$ oil in chloroform $(300 \mathrm{mg} / \mathrm{ml})$ was injected onto the column ODS capcel pak, $\mathrm{C}_{18}$ $(4.4 \times 100 \mathrm{~mm})$. Gradient elution with acetonitrile: dichloromethane (starting from 90: 10 to 35: 65, v/v in $150 \mathrm{~min}$ ) was conducted. FID (with moving band, Tracor 945) was used. The carbon number assignment for the separated peaks was determined using soybean HPLC chromatogram as reference containing 29 triacylglycerols. The first peak (XOX) appeared after 30 minutes, whereas the last peak (SSS) appeared after 72 minutes from the first. Designations of TAGs do not imply the positional acyl distribution in TAG molecules but a mixture of TAG isomers. The following coding was used for fatty acyls: $\mathrm{X}=$ linolenic, $\mathrm{L}=$ linoleic, $\mathrm{O}=$ oleic, $\mathrm{S}=$ stearic and $P=$ palmitic.

\subsection{Whole Sterols by GLC (13)}

Whole sterols were isolated from the unsaponifiables via preparative silica gel $G$ plates using chloroform: diethyl ether: acetic acid (95:4:1, v/v) as developing solvent. The isolated sterols mixture was treated with silylating reagent consisting of two parts of hexamethyl disilazane (HMDS) and one part of trimethyl chlorosilane (TMCS) with 10 parts of dry pyridine as a solvent. After standing for about $15 \mathrm{~min}$ at room temperature, the mixture was directly injected into gas chromatograph. Hewlett-PackardHP 5890-A gas chromatograph was used for whole sterols analysis under the following operating conditions: Column, DB-17 $(0.32 \mathrm{~mm} \times 15 \mathrm{~m}$ with $0.25 \mu \mathrm{m}$ coating) at $250^{\circ} \mathrm{C}$. Detector, FID at $260^{\circ} \mathrm{C}$ carrier gas, Helium $(8.6 \mathrm{ml} / \mathrm{min})$ and split ratio 35:1. The \% peak areas were calculated by electronic integrator.

\subsection{Free Sterols and Acylated Sterols (21)}

Free (FS) and acylated sterols (AS) were isolated from the oil by preparative TLC using n-hexane: ether:acetic acid (70:30:1, v/v) as developing solvent.

The FS $\left(R_{f}=0.16\right)$ and the AS $\left(R_{f}=0.63\right)$ were separately scraped off the plate and extracted with chloroform. The AS fraction was subjected to alkaline hydrolysis to remove the fatty acyl moieties. The obtained and the original FS were subjected to derivatization into 9-anthroyl nitriles (9-AN) according to Wanaka and Murui (15). HPLC of 9-AN was conducted using Toyo-Soda-CCPM instrument under the following operating conditions: Column: ODS-1250Y, Senshu Pak (4.6 x 250mm); Detector: fluorescence (Excitation and Emission wave lengths 360 and $460 \mathrm{~nm}$ ); Elution: isocratic using acetonitrile: dichloromethane $(75: 25, \mathrm{v} / \mathrm{v})$ at flow rate $1 \mathrm{ml} / \mathrm{min}$, the lower detection limit is 80 Picograms.

\subsection{Free (FSG) and Acylated (ASG) Sterylglycosides (22)}

Separation of sterylglycosides, derivatization and HPLC analysis were carried out according to Murui et. al., (16). The oil sample in chloroform was injected into silica gel cartridge (Sep-Pak, Waters) and the mixed sterylglycosides were eluted with chloroform: methanol $(1: 1, v / v)$. The eluted compounds were fractionated with the help of preparative TLC using chloroform:methanol:formic acid (90:15:1, v/v) as a developing solvent. Only ASG was deacylated with alkaline hydrolysis $(0.5 \mathrm{MKOH}$ in isopropanol) to obtain FSG. The obtained and original FSG were separately subjected to 1-anthroylnitrile derivatization (SG-1-AN). 
HPLC was used for SG-1-AN under the following conditions: column ODS Wakosil-5, $\mathrm{C}_{18}(6.4 \times 250 \mathrm{~mm})$; Elution: gradient using acetonitrile: dichloromethane (from 50:50 to 68:32 v/v); Detector: UV and absorption was measured at $254 \mathrm{~nm}$. The method is sensitive to 0.5 nanogram.

It is worthy to mention that 1-anthroylnitrile was used for sterylglycoside (SG) derivatization, instead of 9-anthroylnitrile, due to the steric hinderance of the latter compound. In addition, ASG structure is steryl-B-D(2-or4-O-Fatty-Acyl) glucopyranoside. The molar ratio of fatty acid:sterol is 1:1 (23).

\subsection{Tocopherols (13)}

A sample of $10 \mu$ oil in $n$-hexane (10\% solun) was injected in HPLC column (silica, YMC-A-012, $6.0 \times 150 \mathrm{~mm}$ ). Elution was isocratic using $n$-hexane:isopropyl alcohol $(100: 0.5, \mathrm{v} / \mathrm{v})$ at flow rate $2 \mathrm{ml} / \mathrm{min}$. Hitachi650-10S fluorescence detector was used. Spectral absorption was set at excitation and emission wave lengths (295 and $325 \mathrm{~nm})$.

\subsection{Isopropenoid Alcohols (19)}

A sample of $100 \mathrm{mg}$ oil was dissolved in $5 \mathrm{ml}$ n-hexane:ethyl ether $(98: 2, \mathrm{v} / \mathrm{v})$ and the solution was injected into silica cartridge (equilibrated with the same solvent). The eluted material (isoprenoid esters), was collected and the solvent was removed with a $\mathrm{N}_{2}$ stream. The residue was subjected to alkaline hydrolysis at $100^{\circ} \mathrm{C}$ for 45 minutes using $5 \mathrm{ml}$ of $0.5 \mathrm{M} \mathrm{KOH}$. To the product, $4 \mathrm{ml}$ of $n$-hexane, $14 \mathrm{ml}$ of water and $1 \mathrm{ml}$ of saturated $\mathrm{NaCl}$ solution were added and the mixture was shaken vigorously. The hexane layer; containing wax alcohols, dihydrophytol (DHPY), Phytol (PHY) and geranylgeraniol (GG) was transferred into another tube. $1 \mathrm{ml}$ of this solution was taken into another test tube and the solvent was removed by a stream of $\mathrm{N}_{2}$. To the residue, $1 \mathrm{ml}$ of $n$-hexane: chloroform $(1: 1, \mathrm{v} / \mathrm{v}), 0.1 \mathrm{ml}$ of $0.1 \% 9$-anthroylnitrile in acetonitrile and 3 drops of triethylamine (catalyst) were added and the mixture was heated in Aluminium block heater at $100^{\circ} \mathrm{C}$ for $30 \mathrm{~min}$. The 9-An derivatives were dissolved in a small volume of ethyl acetate and was subsequently fractionated by argenation TLC ( $5 \% \mathrm{Ag})$. Solvent system (n-hexane: diethyl ether: ethanol) $(95: 5: 0.5, \mathrm{v} / \mathrm{v})$ was used as a developing solvent. Two well defined zones on the plate were separately scraped off the plate (the lower zone had $R_{f}=0.3$ and upper one is $2-3 \mathrm{~cm}$ higher) and were transferred into two small screw capped test tubes. Excess reagent appeared as yellow spot between the two zones. Two $\mathrm{ml}$ of isopropyl alcohol and ethyl acetate were added to each tube, heated for 10 minutes and $6 \mathrm{ml}$-portion of water was added to each tube with vigorous shaking. The upper layer in each tube was taken for HPLC analysis. It is worthy to mention that the upper zone scraped off the TLC plate comprised PHY and DHP whereas the lower one contained the highly unsaturated GG. Calibration curve was made using phytol as a standard substance. HPLC analysis was conducted under the following operating conditions: column: TSK GEL ODS-80Ts (4.6 x $150 \mathrm{~mm})$; Elution: gradient using acetonitrile-dichloromethane (100/040/60,48min); Detector:fluorescence (Ex.370 nm, Em. 470nm).

\subsection{Calibration of GLC and HPLC Methods}

All the methods were calibrated with standard substances and all the results recorded were the mean of two concordant replicates.

\section{RESULTS AND DISCUSSION}

\subsection{Triacylglycerols (Tables I, II, III)}

Patterns of triacylglycerols (TAGs) of pure oils, namely, rapeseed, sunflower and corn oils as well as corn admixtures with the other two oils, were elucidated by HPLC. The direct examination of HPLC chromatograms did not enable the determination of oil authenticity. TAGs of XXO, LLL, LLO, LLP, XLS, LOO, LOP, OOO and OOS can be taken for differentiation between the pure oils. However, the detection of rapeseed or sunflower oil in corn via these TAGs is rather difficult.

For simplicity, peak areas \% representing TAGs with ECN 40, 42, 46, 48 and 50 are taken into consideration. However, it was not able to differentiate sharply between the three pure oils or to recognize the adulterating oil in corn admixture.

Therefore, it was found advisable to use the ratios of peak areas \% of TAGs representing ECN of 42,44 and 46 to the peak area \% of TAGs representing ECN 48. The ratios can distinguish easily between one pure oil from the other and can establish adulteration of corn oil. Also one can recognize to some extent the type of the oil incorporated into corn oil. 
Table I

Triacylglycerols Composition \% of Rapeseed, Sunflower and Corn Oils as Determined by RP-HPLC

\begin{tabular}{ccccc}
\hline TAG & ECN & Rapeseed & Sunflower & Corn oil \\
\hline XLL & 40 & 1.4 & 0.2 & 0.8 \\
XXO & 40 & 1.6 & - & - \\
LLL & 42 & 1.5 & 19.4 & 20.7 \\
XLO & 42 & 6.8 & 0.2 & 1.1 \\
XLP & 42 & 1.2 & 0.1 & 0.2 \\
LLO & 44 & 9.0 & 26.4 & 22.1 \\
XOO & 44 & 9.3 & - & - \\
LLP & & & & \\
XLS & 44 & 1.2 & 8.5 & 14.9 \\
LOO & 46 & 22.4 & 20.6 & 12.0 \\
LLS & & & & \\
& 46 & 5.5 & 13.2 & 12.8 \\
LOP & & & & \\
LPP & 46 & - & 1.4 & 2.0 \\
OOO & 48 & 23.0 & 3.9 & 4.1 \\
LOS & 48 & 1.6 & 4.6 & 1.8 \\
OOP & 48 & 4.0 & 1.8 & 3.3 \\
LSP & 48 & 0.2 & 1.1 & 0.6 \\
POP & 48 & 0.6 & 0.2 & 0.8 \\
OOS & 50 & 1.7 & 2.7 & 0.7 \\
LSS & 50 & 0.3 & 0.5 & 0.5 \\
POS & 50 & 0.3 & 0.4 & 0.8 \\
\hline X & & & &
\end{tabular}

$X, L, O, S$ and $P$ denote: Linolenic, Linoleic, Oleic, Stearic and Palmitic respectively.

Table II

Triacylglycerols Composition of Corn Oil Admixed with Rapeseed and Sunflower Oils as Determined by RP-HPLC

\begin{tabular}{cccccc}
\hline TAGS & ECN & $\begin{array}{c}\text { Corn Admixed with } \\
\text { 5\% Rapeseed }\end{array}$ & $\begin{array}{c}\text { 10\% Rapeseed } \\
\text { 5\% }\end{array}$ & $\begin{array}{c}\text { Corn Oil Admixed with } \\
\text { Sunflorer }\end{array}$ & 10\% Sunflower \\
\hline XLL & 40 & 0.9 & 0.9 & 1.0 & 0.8 \\
XXO & 40 & - & 0.2 & - & - \\
LLL & 42 & 19.2 & 18.2 & 19.3 & 20.3 \\
XLO & 42 & 0.9 & 1.2 & 0.8 & 0.8 \\
XLP & 42 & 0.3 & 0.4 & 0.6 & 0.4 \\
LLO & 44 & 21.5 & 20.2 & 21.2 & 22.5 \\
XOO & 44 & 0.9 & 1.2 & - & - \\
LLP & & & & & \\
\} & 44 & 14.3 & 14.0 & 13.4 & 13.8 \\
XLS & & & & & \\
LOO & 46 & 12.8 & 13.1 & 12.1 & 12.4 \\
LLS & & & & & \\
\} & 46 & 12.3 & 11.9 & 12.5 & 12.7 \\
LOP & & & & & \\
LPP & & & & & \\
\} & 46 & 1.9 & 1.8 & 2.2 & 1.9 \\
XSP & & & & & \\
OOO & 48 & 5.7 & 7.4 & 4.4 & 4.2 \\
LOS & 48 & 1.8 & 1.9 & 2.1 & 2.1 \\
OOP & 48 & 3.5 & 3.6 & 3.2 & 3.3 \\
LSP & 48 & 0.6 & 0.6 & 1.0 & 0.7 \\
POP & 48 & 0.8 & 0.7 & 1.2 & 0.8 \\
OOS & 50 & 1.3 & 1.4 & 1.2 & 1.9 \\
LSS & 50 & 0.4 & 0.4 & 0.5 & 0.3 \\
POS & 50 & 0.3 & 0.4 & 0.6 & 0.3 \\
\hline
\end{tabular}

$X, L, O, S$ and $P$ denote: Linolenic, Linoleic, Oleic, Stearic and Palmitic respectively.
Table III

Triacylglycerol Composition as Determined by RP-HPLC Analysis

\begin{tabular}{lcccccccccc}
\hline \multicolumn{1}{c}{ Sample } & \multicolumn{4}{c}{ Area \% of Peak with ECN* } & \multicolumn{5}{c}{ Ratio of ECN } \\
& 40 & 42 & 44 & 46 & 48 & 50 & $42 / 48$ & $44 / 48$ & $46 / 48$ \\
\hline Pure Oils: & & & & & & & & & \\
Rapeseed (Rs) & 3.0 & 9.5 & 19.5 & 27.9 & 29.4 & 2.3 & 0.32 & 0.66 & 0.95 \\
Sunflowers (SN) & 0.2 & 19.7 & 34.9 & 25.2 & 11.6 & 3.6 & 1.70 & 3.00 & 2.17 \\
Corn (Cr) & 0.8 & 22.0 & 37.0 & 26.8 & 10.7 & 2.0 & 2.06 & 3.46 & 2.50 \\
Admixtures: & & & & & & & & & \\
$5 \%$ Rs in Cr & 0.9 & 20.4 & 35.7 & 27.0 & 12.4 & 2.0 & 1.65 & 2.88 & 2.18 \\
$10 \%$ Rs in Cr & 1.1 & 19.8 & 34.4 & 26.8 & 14.2 & 2.2 & 1.39 & 2.42 & 1.89 \\
$5 \%$ SN in Cr & 1.0 & 20.7 & 34.6 & 26.8 & 12.1 & 2.3 & 1.71 & 2.86 & 2.21 \\
$10 \% \mathrm{SN}$ in Cr & 0.8 & 21.5 & 36.3 & 27.0 & 11.1 & 2.5 & 1.94 & 3.30 & 2.43 \\
\hline
\end{tabular}

(*) $\mathrm{ECN}=$ Equivalent Carbon Number: Carbon Number $-2 \mathrm{X}$ Number of D-Bonds.

\subsection{Whole Sterols (Table IV)}

Prior to analysis, pure sterols are isolated from the unsaponifiable fraction of the oil and then converted into silyl ethers. From the results, it is clear that rapeseed, sunflower and corn oil exhibit very characteristic sterol patterns. This is due to the fact that each oil has one or more characteristic sterol thus, rapeseed oil contains brassicasterol, whereas sunflower has 7-avenasterol and 7-stigmastenol. Corn oil has comparatively higher sitosterol than the other two oils and comparatively moderate amount of 5-stigmasterol.

Thus, the authenticity of corn oil can be proved from these specific sterols. Detection of admixtures can be accomplished by the presence of lower amounts of brassica - or 7 avena-sterol plus 7-stigmastenol. Trying to apply the ratio sitosterol / [campesterol + 5stigmasterol], $®$, it is found that it is not easy to ensure the presence of rapeseed or sunflower oil incorporated as adulterants in corn oil. The $\mathrm{R}$ values are nearly similar in the admixtures.

Generally any specific sterol can be taken as purity criterion and hence establish the adulteration of corn oil with such oils. The whole sterols seem to be derived from different sterol structures, therefore, it is advisable to deal with more definitive sterol lipid groups and to determine their specific sterol patterns of oils and their admixtures. These sterol groups include free and acylated forms of sterols and sterylglycosides which can provide more definitive information instead of the whole sterols.

\subsection{The Free (FS) and Acylated Sterols (AS) (Table V)}

The FS and AS fractions of the oil, are isolated via preparative thin layer into two zones having $R_{f}$ value of 0.16 and 0.63 respectively. The derivatives of 9-anthroylnitriles are subjected to RP-HPLC and separated according to the following sequence: avena-, isofuco-, brassica-, chole-, campe-plus-5-stigma-, 7-stigma- and finally sito-steryl 9-AN. 
Table IV

Whole Sterol Compositions as Determined by Capillary GLC as their TMS Ether Derivatives

\begin{tabular}{|c|c|c|c|c|c|c|c|c|c|}
\hline \multirow{2}{*}{ Sample } & \multicolumn{8}{|c|}{ Whole Sterol Composition \% } & \multirow{2}{*}{ Ratio (R) } \\
\hline & Total \% & Brass. & Campe. & 5-Stigma. & Sitost. & Isofuco* & 7-Stigmastenol & 7-Avena & \\
\hline \multicolumn{10}{|l|}{ Pure Oils: } \\
\hline Rapeseed (Rs) & 0.85 & 11.0 & $(22.6)$ & 2.0 & 61.4 & 3.0 & - & - & 2.49 \\
\hline Sunflower (SN) & 0.91 & - & 9.1 & 11.1 & 60.4 & 3.5 & 11.7 & 4.2 & 3.00 \\
\hline Corn $(\mathrm{Cr})$ & 1.0 & - & 21.5 & 7.2 & 67.8 & 3.5 & - & - & 2.36 \\
\hline \multicolumn{10}{|l|}{ Admixtures: } \\
\hline $5 \% \mathrm{Rs}$ in $\mathrm{Cr}$ & 0.99 & 0.4 & 21.8 & 6.9 & 67.6 & 3.3 & - & - & 2.36 \\
\hline $10 \% \mathrm{Rs}$ in $\mathrm{Cr}$ & 0.97 & 0.9 & 21.8 & 6.8 & 67.2 & 3.4 & - & - & 2.35 \\
\hline $5 \% \mathrm{SN}$ in $\mathrm{Cr}$ & 1.00 & - & 20.9 & 7.5 & 67.4 & 3.5 & 0.5 & 0.2 & 2.37 \\
\hline $10 \% \mathrm{SN}$ in $\mathrm{Cr}$ & 0.97 & - & 20.3 & 7.8 & 67.0 & 3.5 & 0.9 & 0.5 & 2.38 \\
\hline
\end{tabular}

(R): Sitosterol / [campesterol + 5-stigmasterol].

* Isofucosterol has the same structure and configuration as 5-avenasterol.

Table V

Free (FS) and Acylated Sterols (AS) Composition as Determined by HPLC as their 9-Anthroylnitriles

\begin{tabular}{|c|c|c|c|c|c|c|c|c|c|c|c|c|c|c|}
\hline \multirow{2}{*}{ Sample } & \multirow{2}{*}{\multicolumn{2}{|c|}{$\begin{array}{c}\text { Total } \\
\text { (mg/100g) }\end{array}$}} & \multicolumn{10}{|c|}{ FS and AS Sterol composition \% } & \multirow{2}{*}{\multicolumn{2}{|c|}{ Ratio (R) }} \\
\hline & & & \multicolumn{2}{|c|}{ 7-Avena. } & \multicolumn{2}{|c|}{ Isofuco } & \multicolumn{2}{|c|}{ Brassica. } & \multicolumn{2}{|c|}{ Campe + Stigma. } & \multicolumn{2}{|c|}{ Sitost. } & & \\
\hline \multirow[t]{2}{*}{ Rapeseed (Rs) } & FS & 240 & - & & - & & 8.2 & & 28.4 & & 63.4 & & 2.23 & \\
\hline & AS & 290 & & - & & 3.1 & & 6.3 & & 33.1 & & 57.5 & & 1.74 \\
\hline \multirow[t]{2}{*}{ Sunflower (SN) } & FS & 180 & 3.2 & & 5.0 & & - & & 21.5 & & $70.3^{\star}$ & & 3.27 & \\
\hline & AS & 50 & & 4.0 & & 2.4 & & - & & 27.9 & & $65.7^{*}$ & & 2.35 \\
\hline \multirow[t]{2}{*}{ Corn (Cr) } & FS & 370 & - & & 3.3 & & - & & 30.4 & & 66.3 & & 2.15 & \\
\hline & AS & 360 & & - & & 5.0 & & - & & 26.5 & & 68.5 & & 2.58 \\
\hline \multicolumn{15}{|l|}{ Admixtures: } \\
\hline \multirow[t]{2}{*}{$5 \% \mathrm{Rs}$ in $\mathrm{Cr}$} & FS & 364 & - & & 3.2 & & 0.30 & & 30.5 & & 66.3 & & 2.17 & \\
\hline & AS & 355 & & - & & 5.8 & & 0.20 & & 25.8 & & 68.4 & & 2.65 \\
\hline \multirow[t]{2}{*}{$10 \% \mathrm{Rs}$ in $\mathrm{Cr}$} & FS & 358 & - & & 3.0 & & 0.4 & & 30.2 & & 66.4 & & 2.20 & \\
\hline & AS & 351 & & - & & 5.4 & & 0.6 & & 26.4 & & 67.6 & & 2.56 \\
\hline \multirow[t]{2}{*}{$5 \% \mathrm{SN}$ in $\mathrm{Cr}$} & FS & 361 & 0.10 & & 3.4 & & - & & 30.1 & & $66.4^{\star}$ & & 2.21 & \\
\hline & AS & 344 & & 0.15 & & 5.6 & & - & & 26.0 & & $68.3^{*}$ & & 2.63 \\
\hline \multirow[t]{2}{*}{$10 \% \mathrm{SN}$ in $\mathrm{Cr}$} & FS & 350 & 0.20 & & 3.7 & & - & & 29.6 & & $66.5^{*}$ & & 2.25 & \\
\hline & AS & 330 & & 0.30 & & 5.4 & & - & & 26.4 & & $67.9^{*}$ & & 2.57 \\
\hline
\end{tabular}

(R): Sitosterol / [campesterol + 5-stigmasterol].

* Plus 7-Stigmastenol (Sunflower contains 10 and $5 \mathrm{mg} / 100 \mathrm{~g}$ oil 7 -Stigmastenol in FS and AS).

The total contents of FS and AS (mg/100g oil) can primarily differentiate between pure oils and corn oil admixtures on one hand, and can help, to some extent, recognize the added oil to corn, but not its level.

Concerning the distribution of sterols in FS and AS fractions, it is found that characteristic sterols can help determine oil authenticity (brassicasterol in rape, 7-avenasterol and 7-stigmastenol in sunflower oil). In addition, the presence of lower amounts of these sterols is a useful means for detecting corn oil admixtures.

Using the ratio $\mathrm{R}$ [sitosterol / (campe - + 5stigmasterol)], it is noted that it is satisfactory for 
differentiating pure oils from one another, but is somewhat difficult to detect admixtures. Accordingly the $R$ value can not decisively establish oil adulteration, since $R$ values of the corn admixtures are nearly similar. The ratio of FS content to that of AS can help in determining oil authenticity but can not definitely detect corn oil admixtures, since the values are nearly similar for three corn admixtures. However, only corn oil admixed with $10 \%$ sunflower oil exhibits a very distinguished FS/AS value (1.11). FS/AS values of pure oils and their admixtures can be illustrated as follows:
Pure oils:

$\begin{array}{ll}\text { Rapeseed } & 0.83 \\ \text { Sunflower } & 3.60 \\ \text { Corn } & 1.03\end{array}$

\section{Corn oil admixtures:}

$\begin{array}{ll}5 \% \text { rape } & 1.03 \\ 10 \% \text { rape } & 1.00 \\ 5 \% \text { sunflower } & 1.05 \\ 10 \% \text { sunflower } & 1.11\end{array}$

\subsection{Free (FSG) and Acylated (ASG) Sterylglycosides (Table VI)}

Steryl- $\beta$-D-glucopyranosides and steryl- $\beta$-D-(2 or 4-O-Fatty Acyl) glucopyranosides are the structures of FSG and ASG respectively (21). The isolated fractions are derivatized into 1-anthroylnitriles (instead of 9-anthroylnitriles) due to the steric hinderance (20).

The total FSG and ASG contents and in particular the ASG content of corn oil is exceedingly higher than those of rapeseed and sunflower oils. Concerning the sterylglycosides distribution in each fraction, it is striking that 7-avenasterylglycoside (7-AV-SG), being a specific component in sunflower, is also detected in rapeseed and corn oils. In addition, the ASG fraction of corn oil is very rich in avena-SG than that of rapeseed and even in sunflower. This is considered as a new characterization of corn oil which has not been hitherto reported. By this approach one can differentiate between pure oils and can, to some extent, detect corn oil adulteration. With reference to other SG components, it is apparent that isofuco-SG, campe- + stigma $S G$ and sito-SG are present in exceedingly higher amounts (expressed as ppm) in the ASG fraction of corn oil than the two other oils. This means that the ASG fraction of corn oil is highly enriched in the sterylglycosides than the FSG which is not the case with the other oils. This characterization can be taken as purity criterion for establishing corn oil authenticity. In addition, the detection of 7-stigmastenol and/or brassicasterolglycosides even in minor quantities reveals corn oil adulteration.

Table VI

\section{Free (FSG) and Acylated Sterylglycosides (ASG) Composition as Determined by HPLC as their 1-Anthroylnitriles}

\begin{tabular}{|c|c|c|c|c|c|c|c|c|c|c|c|c|c|}
\hline \multirow{2}{*}{ Sample } & \multirow{2}{*}{\multicolumn{2}{|c|}{$\begin{array}{l}\text { Total } \\
(\mathrm{ppm})\end{array}$}} & \multicolumn{10}{|c|}{ Steryl Glycosides Composition \% } & \multirow{2}{*}{ Ratio (R) } \\
\hline & & & 7-Avena. & Isofuco & Brassica. & \multicolumn{2}{|c|}{ Unk. } & \multicolumn{2}{|c|}{ Campe + Stigma. } & \multicolumn{2}{|c|}{ 7-Stigma. } & Sitost. & \\
\hline \multicolumn{3}{|l|}{ Pure Oils: } & & & & & & & & & & & \\
\hline \multirow[t]{2}{*}{ Rapeseed (Rs) } & FSG & 146 & 1.6 & 2.0 & 5.2 & - & & 19.0 & & - & & 72.4 & 3.81 \\
\hline & ASG & 81 & 1.3 & 3.0 & 4.1 & & 0.5 & & 21.9 & & - & 69.2 & 3.16 \\
\hline \multirow[t]{2}{*}{ Sunflower (SN) } & FSG & 200 & 2.0 & 7.5 & - & 1.2 & & 11.7 & & 1.6 & & 76.6 & 6.55 \\
\hline & ASG & 174 & 0.9 & 3.4 & - & & 0.8 & & 14.5 & & 1.9 & 78.5 & 5.41 \\
\hline \multirow[t]{2}{*}{ Corn $(\mathrm{Cr})$} & FSG & 105 & 1.8 & 3.7 & - & - & & 22.5 & & - & & 72.0 & 3.2 \\
\hline & ASG & 1553 & 1.1 & 3.3 & - & & - & & 27.9 & & - & 67.7 & 2.43 \\
\hline \multicolumn{14}{|l|}{ Admixtures: } \\
\hline \multirow[t]{2}{*}{$5 \% \mathrm{Rs}$ in $\mathrm{Cr}$} & FSG & 107 & 1.8 & 3.6 & 0.3 & - & & 22.0 & & - & & 72.3 & 3.29 \\
\hline & ASG & 1483 & 1.2 & 4.0 & 0.2 & & - & & 27.0 & & - & 67.8 & 2.51 \\
\hline \multirow[t]{2}{*}{$10 \% \mathrm{Rs}$ in $\mathrm{Cr}$} & FSG & 109 & 1.9 & 4.0 & 0.5 & - & & 21.0 & & - & & 72.0 & 3.43 \\
\hline & ASG & 1409 & 1.0 & 4.1 & 0.3 & & - & & 26.6 & & - & 68.0 & 2.56 \\
\hline \multirow[t]{2}{*}{$5 \% \mathrm{SN}$ in $\mathrm{Cr}$} & FSG & 111 & 2.1 & 4.8 & - & - & & 20.9 & & Tr. & & 72.2 & 3.45 \\
\hline & ASG & 1486 & 1.0 & 2.8 & - & & - & & 27.5 & & 0.1 & 68.6 & 2.49 \\
\hline \multirow[t]{2}{*}{$10 \% \mathrm{SN}$ in $\mathrm{Cr}$} & FSG & 114 & 2.0 & 4.4 & - & - & & 20.0 & & 0.1 & & 73.5 & 3.70 \\
\hline & ASG & 1420 & 0.9 & 3.0 & - & & 0.1 & & 26.0 & & 0.2 & 69.8 & 2.68 \\
\hline
\end{tabular}

(R): Sitosterol / [campesterol + 5-stigmasterol]. 
Concerning, the $\mathrm{R}$ ratio of sitosterylglycoside to the sum of 5-campe- and 5-stigmasterylglycoside in FSG and ASG fractions, one can differentiate between pure oils and their admixtures. Accordingly, $R$ ratio can be used as suitable means for detecting corn oil adulteration.

With reference to the weight ratio FSG/ASG of pure oils and their admixtures, one can characterize easily corn oil from the other two oils, however, it is not able to detect oil admixtures since the ratios are nearly similar to that of pure corn oil. The FSG/ASG ratios of pure oil can be depicted as follows:

\section{FSG/ASG}

Pure oils:

Corn oil admixed with:

$\begin{array}{llll}\text { Rapeseed } & 1.80 & 5 \% \text { Rapeseed } & 0.07 \\ \text { Sunflower } & 1.15 & 10 \% \text { Rapeseed } & 0.08 \\ \text { Corn } & 0.07 & 5 \% \text { Sunflower } & 0.07 \\ & & 10 \% \text { Sunflower } & 0.08\end{array}$

\subsection{Tocopherols (Table VII)}

The total contents of the tocopherols in corn oil is noticeably higher than those in rapeseed and sunflower oils. Therefore, the incorporation of any oil into corn oil lowers inevitably the total tocopherol content.

With reference to the tocopherol patterns of the pure oils, it is noticed that corn oil contains $82.0 \%$ gamma-T and $15.4 \%$ alpha-T corresponding to 77.0 $\%$ and $21.1 \%$ in rapeseed oil. However, sunflower oil has different pattern in which alpha-T constitutes $95.0 \%$ of the total tocopherols. On the other side any addition of rapeseed or sunflower oil gives admixtures having rather different tocopherol patterns which are either similar to that of corn or rapeseed oil.

In attempt to establish oil adulteration, the ratio gamma-T/alpha-T is used. Thus, the ratio for corn is 5.32 and when the oil is admixed with $5 \%$ or $10 \%$ rapeseed, the ratio decreases to 5.16 and $5.02 \%$ respectively. Meanwhile, when sunflower oil is incorporated into corn oil at $5 \%$ and $10 \%$, the corresponding ratios are 4.51 and 3.22. In the light of these ratios it seems possible to recognize the adulterant incorporated into corn oil.

Generally, the total content of tocopherol, the level of certain tocopherol constituents as well as the ratio of gamma-T/alpha-T are useful parameters for establishing corn oil purity.
Table VII

Tocopherols Composition as Determined by HPLC

\begin{tabular}{|c|c|c|c|c|c|c|}
\hline \multirow{2}{*}{ Sample } & \multirow{2}{*}{$\begin{array}{c}\text { Total } \\
(\mathrm{ppm})\end{array}$} & \multicolumn{4}{|c|}{ Tocopherols Composition \% } & \multirow{2}{*}{$\frac{\text { Gamma-T }}{\text { Alpha-T }}$} \\
\hline & & Alpha-T & Beta-T & Gamma-T & Delta-D & \\
\hline \multicolumn{7}{|l|}{ Pure oils: } \\
\hline Rapeseed (Rs) & 650 & 21.1 & - & 77.0 & 1.7 & 3.65 \\
\hline Sunflower (SN) & 510 & 95.0 & 3.2 & 1.0 & 0.8 & 0.011 \\
\hline Corn (Cr) & 1017 & 15.4 & 0.5 & 82.0 & 2.3 & 5.32 \\
\hline \multicolumn{7}{|l|}{ Admixtures: } \\
\hline $5 \% \mathrm{Rs}$ in $\mathrm{Cr}$ & 1012 & 15.8 & 0.4 & 81.6 & 2.2 & 5.16 \\
\hline $10 \% \mathrm{Rs}$ in $\mathrm{Cr}$ & 1010 & 16.2 & 0.3 & 81.3 & 2.2 & 5.02 \\
\hline $5 \% \mathrm{SN}$ in $\mathrm{Cr}$ & 1014 & 17.5 & 1.2 & 79.0 & 2.3 & 4.51 \\
\hline $10 \% \mathrm{SN}$ in $\mathrm{Cr}$ & 1012 & 23.0 & 0.8 & 74.0 & 2.2 & 3.22 \\
\hline
\end{tabular}

\subsection{Isoprenoid Alcohols (Table VIII)}

Isoprenoid alcohols (ISPAs), namely phytol (PHY), dihydrophytol (DHP) and geranylgeraniol (GG) have been determined in pure oils and their admixtures.

The total ISPAs content in the pure oils varies markedly representing 286,313 and $77.0 \mathrm{ppm}$ in rapeseed, sunflower and corn oil. Therefore, it is easy to differentiate between the three pure oils. In corn oil admixed with the two oils the total IPAs content ranges from 88.0 to $102 \mathrm{ppm}$.

Referring to the IPAs patterns, PHY constitutes $95.1 \%(272 \mathrm{ppm})$ in rapeseed oil, $32.3 \%$ (101 ppm) in sunflower and $7.7 \%(6.0 \mathrm{ppm})$ in corn oil. Therefore, one can easily differentiate between the three oils via their PHY contents. In case of corn oil admixed with 5 and $10 \%$ rapeseed oil, PHY constitutes $22.5 \%$ (20.0ppm) and $31.1 \%$ (29.0ppm) respectively. On the other side, when corn oil is admixed with 5 and $10 \%$ sunflower oil, PHY forms 11.4 (10.0ppm) and $16.5 \%(17.0 \mathrm{ppm})$ respectively. Therefore, PHY is considered as a useful parameter in establishing adulteration and in recognizing the adulterant type in the oil. DHP seems to be insignificant in determining oil authenticity since no marked variation in its amount is observed. On the other side, GG constitutes $90.9 \%$ (70.0ppm) of the total IPAs in corn oil whereas it amounts to $67.4 \%(211 \mathrm{ppm})$ in sunflower and $3.8 \%$ (11.0ppm) in rapeseed oil. On the basis of this observation, one can differentiate the three pure oils from one another and between pure oils and corn oil admixed only with 5 and $10 \%$ sunflower. Generally, PHY and GG contents can be taken as useful means for establishing corn oil authenticity.

Alternatively $\mathrm{PHY} / \mathrm{GG}$ ratio is proposed for determining authentication of corn oil. It is found that the three oils can be easily distinguished by this ratio and can also detect corn oil admixtures. In addition, this ratio can be used for recognizing the adulterant oil in corn oil admixtures. 
Table VIII

Isoprenoid Alcohols Composition as Determined by HPLC as their 9-Anthroylnitriles

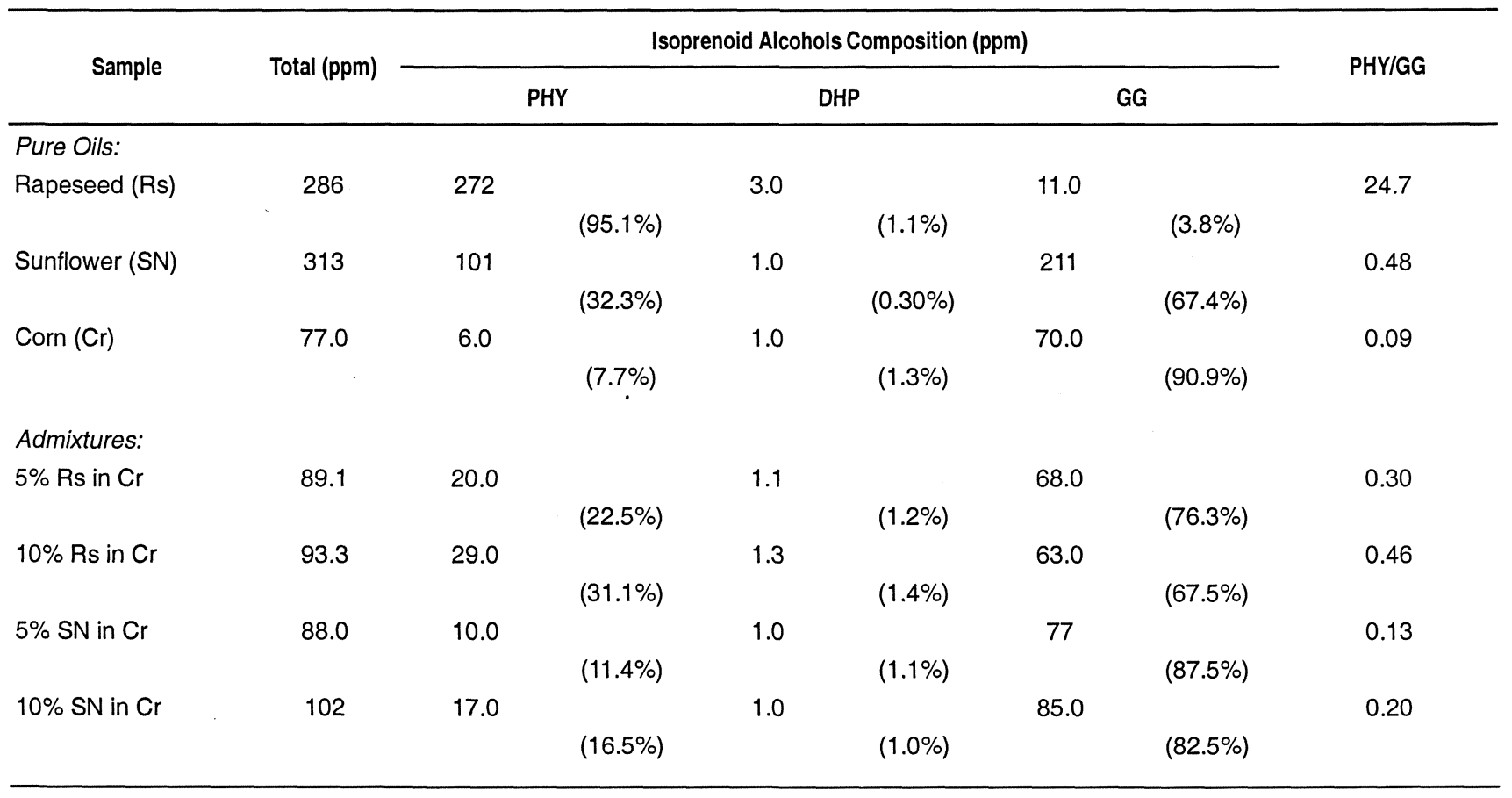

PHY: Phytol. DHP: Dihydrophytol. GG: Gernyl Geraniol Cottonseed Isoprenoids (ppm): PHY, 40; DHP, 120 and

\section{CONCLUSION}

It is finally concluded that the contents and compositions of minor components FS, AS, FSG and ASG; tocopherols and IPAs, in combination of TAGs, are generally more advantageous in establishing corn oil authenticity. However, determination of oil IPAs is more decisive for proving oil authentication. The HPLC methods, used in the analysis of the oil components, are very efficient for elucidating the different lipid profiles in an accurate manner.

Meanwhile, there are certain parameters, including new ones, that can be taken into consideration for establishing corn oil purity and in detecting its admixtures:

1.- The detection of characteristic components in sterols, isoprenoid alcohols, tocopherols and triacylglycerols.

2.- The use of the ratio of peak area\% of TAG with certain ECN value to the peak area\% of TAG having higher ECN value (e.g. 44/48).

3. - The total contents of FS plus AS as well as FSG plus ASG as well as their weight ratios FS/AS and $F S G / A S G$.

4.- The total content of oil tocopherols, and the ratio of one component to the other (e.g. gamma-T/alpha-T).
GG, 76; PHY/GG: 0.53 .
5.- The total contents of IPAs, their concentrations and the weight ratio of one component to the other (e.g. PHY/GG).

Item 3 and 5 are considered as new purity criteria for corn oil. In addition, total sterols, tocopherols and isoprenoids are useful parameters for corn oil authentication.

It is noteworthy that natural variability of the components in the oils from different origins can modify the detection levels.

\section{REFERENCES}

I. Mani, V.V.S and Lakshminarayana, G. (1968)."Chromatographic Detection of Adulteration of Oils and Fats".-Chromatographic Reviews. 10, 159-163.

.2. Kaimal, T.N.B.; Mani, V.V.S., Achaya; K.T. and Laksminarayana, G. (1974).— —Detection of Mustard Seed, Soyabeen and Safflower Seed Oils in Groundnut Oil by TLC».-J.Chromatography. 100, 243-247

3. Imai, C.; Watanabe, H.; Haga, N. and T.11, Q.P Corporation (1974). - «Detection of Adulteration of Cottonseed Oil by Gas Liquid Chromatography".JAOCS, 51, 326-330.

4. Jha, J.S. (1980). - «Spectrophotometric Studies of Rice Bran Oil and Mustard Oil Mixtures".-JAOCS, $57,83-86$. 
5. Ramakrishna, G.; Azeemoiddin, G. and Thirumala R.S.D. (1979). - «Detection of Pongam Oil Using Acetic Anhydride Sulphuric Acid Reagent".-J. Fd. Sci. and Technol. (India) 16, 172-176.

6. Gillatt, P. and Rossell, J.B. (1992).- «Oils and Fats Research at Leatherhead Food RA».-Inform. 3, 586-590.

7. Li-Chan, E. (1994).- «Developments in the Detection of Adulteration of Olive Oil».-Trends in Food Science and Technology. 5, 1-11.

8. Krishnamurthy M.N. (1993)._- «Updated Methods for Detection of Adulterants and Contaminants in Edible Oils and Fats».-A Critical of Review. J. Food Sci. Technol. 30, 231-238.

9. Woodbury S.E.; Evershed R.P.; Rossell, J.B.; Griffith, R.E. and Farnell P. (1995).- - "Detection of Vegetable Oil Adulteration Using Gas Chromatography Combustion/ Isotope Ratio Mass Spectrometry".-Analytical Chem. $57,2685-2690$.

10. Rossell, J.B. (1994).— «Stable Carbon Isotope Ratios in Establishing Maize Oil Purity».-Fat Sci. Technol. 96, 304-308.

11. El-Hamady, A.H. and Perkins, E.G. (1981)."Reverse Phase HPLC of Natural Triglyceride Mixtures».-Critical Pair Separation. JAOCS 58, 868-872.

12. Peterson, B.; Podlaha, O. and Toregard, B. (1981)."HPLC Separation of Natural Oil Triglycerides into Fractions with the Same Carbon Number and Numbers of Double Bonds".-JAOCS, 58, 1005-1009

13. El-Mallah, M.H.; Murui, T. and El-Shami, S. (1994)."Detailed Studies on Seed Oil of Salicornia SOS-7 Cultivated at the Egyptian Border of Red Sea".Grasas Y Aceites. 54, 385-389.

14. Hwang Jenn-Kang and Yen Gow-Chin. (1982)."Detection of Vegetable Oil Adulteration by HPLC Analysis of Triglycerides".-Presented at the International Conference on Chemistry and World Food Supplies, Dec. 6-10. Manila, Phillipines.
15. Salivaras E. and MC Curdy A.R. (1992).- «Detection of Olive Oil Adulteration with Canola Oil from Triacylglycerol Analysis by RP-HPLC».-JAOCS, 69, 935-938.

16. Salivaras E. (1992).- "Detection of Adulteration of Olive Oil with Canola and other Seed Oils by Reversed-Phase HPLC».-Submitted for the Degree of M.Sc., University of Saskatchewan, Saskatoon, April.

17. Murui, T. and Shouge, J. (1996).-—Determination of Triacylglycerol Composition of Vegetable Oil and Application to Identifying The Components of OilAdmixture".-Yukagaku, 45, 29-36.

18. Grob, K; Giuffre , A.M. Leuzzi, U. and Mincione, B. (1994). - «Recognition of Adulterated Oils by Direct Analysis of Minor Components».-Fat Sci Technol. 96, 286-290.

19. Murui, T and Kamei, Y. (1995).- - ¿Determination of Isoprenoid Alcohols in Vegetable Oils and Application to Cottonseed Detection».-Yukagaku, 44, 14-18.

20. Gordon, M.H. and Miller A.D. (1997).— -Development of Steryl Ester Analysis for the Detection of Admixtures of Vegetable Oils".-JAOCS, 74, 505-510.

21. Wanaka, K. and Murui, T. (1992). - «Determination of Sterols in Edible Oils and Fats by HPLC with Fluorescence Labelling".-Yukagaku, 41, 18-23.

22. Murui, T. and Wanaka K. (1993)._- «Measurement of Sterylglycosides by HPLC with 1-Anthroyl-nitrile Derivatives".-Biosci. Biochem. 57, 614-617.

23. Stenov, K.L and Papov, A.D. (1976).-«Esterified Sterol Glycosides From Sunflower Seed Lipids".Comptes Rendus del Academie Bulgare des Sciences, 29, 1463-1465. 